\title{
Erratum to: Intention Perception in High Functioning People with Autism Spectrum Disorders Using Animacy Displays Derived from Human Actions
}

Phil McAleer $\cdot$ Jim W. Kay $\cdot$ Frank E. Pollick •

M. D. Rutherford

Published online: 3 December 2010

(C) Springer Science+Business Media, LLC 2010

Erratum to: J Autism Dev Disord

DOI 10.1007/s10803-010-1130-8

The authors would like to make a correction to the affiliation of author Frank E. Pollick which was erroneously stated in the manuscript. In contrast to what is currently stated, Prof. Pollick's affiliation should read as of the School of Psychology, University of Glasgow, Glasgow, G12 8QB.

The online version of the original article can be found under doi:10.1007/s10803-010-1130-8.

P. McAleer $(\bowtie)$

Institute of Neuroscience and Psychology and the School of Psychology, University of Glasgow, 58 Hillhead St,

Glasgow G12 8QB, UK

e-mail: phil@psy.gla.ac.uk

J. W. Kay

School of Mathematics and Statistics, University of Glasgow,

Glasgow, UK

M. D. Rutherford

Department of Psychology, Neuroscience and Behaviour,

McMaster University, Hamilton, ON, Canada

F. E. Pollick

School of Psychology, University of Glasgow,

Glasgow G12 8QB, UK 